УДК 264-1:281.9(571.1/.5-22):339.138

DOI: $10.32340 / 2514-772 X-2020-1-64-69$

Г. В. Оленина, доктор педагогических наук, профессор Алтайский государственный институт культуры (Барнаул, Россия) ustlama@mail.ru

Я. А. Ивонина, кандидат исторических наук, доцент Алтайский государственный институт культуры (Барнаул, Россия) yana-ol@mail.ru

\title{
ТРАДИЦИОННЫЕ ПРАВОСЛАВНЫЕ ПРАЗДНИКИ В СОЦИАЛЬНО-КУЛЬТУРНОМ ПРОСТРАНСТВЕ СОВРЕМЕННОГО СИБИРСКОГО СЕЛА: МАРКЕТИНГОВЫЙ ПОДХОД
}

Аннотация. Охарактеризована социально-коммуникативная и социально-педагогическая роль народного праздника, рассматриваемого авторами в качестве крупной формы массовой досуговой активности, в системе межпоколенной трансляции духовно-нравственных ценностей. Перечислен ряд ключевых факторов, под определяющим влиянием которых формируются основы традиционной праздничной культуры различных этнических сообществ. Исследователи констатируют возвращение общецерковных торжеств Русской Православной Церкви в народный праздничный календарь современной России. Авторы рекомендуют профессионалам сферы досуга, занятым организацией и проведением культурно-досуговых программ и акций в условиях современного сибирского села, опираться в работе на технологию социального маркетинга, позволяющую оптимизировать процессы управления материально-технической базой организации праздничных событий и обеспечивать присутствие личностно-развивающего образовательнопросветительного компонента в структуре идейно-тематического замысла массового праздника, связанного с датами христианского календаря.

Ключевые слова: православные праздники, традичии празднования, организачия православных праздников, сочиальный маркетинг, современное сибирское село.

Праздник является крупнейшей формой культуры, вершиной досуговой «лестницы», если под её ступенями понимать формы сменяющей друг друга досуговой деятельности человека, начиная от отдыха и развлечений, просвещения, творчества, созерцания и заканчивая праздником как «систематической и завершающей формой досуга» $[1$, с. 11].

Историко-культурные корни праздника миф и обряд, у праздника есть сакральное ценностное ядро, передающее духовно-нравственную информацию всем празднующим с помощью системы ритуалов, обычаев, традиций. Являясь событийным воплощением мифа об изобильном и счастливом «золотом веке» предков [2], праздник влияет на мировоззрение, регулирует поведение людей в каждой конкретной ситуации празднования. С учётом амбивалентности праздника, т.е. его нравственной двойственности, когда праздничное торжество может перерасти в разгул, обжорство, пьянство, драки и т. д., о котором писал М.М. Бахтин [3], и что особенно часто проявлялось как исторически сложившаяся непременная традиция празднования в Сибири [4, с. 178-179], организатору праздников в современном сибирском селе проходится действовать в довольно сложных обстоятельствах.

В этом случае необходимо учитывать, что традиции празднования складываются у каждого конкретного народа в зависимости от характера труда, быта, климата, географического положения страны, ее исторического опыта, веры и нравственно-этического кода поведения людей. Кроме того, важно помнить, что, будучи явлением многофункциональным, повторяющимся, социально и психологически значимым, праздник не мог не использоваться институтами государства и церкви. Но отношения между институтом праздника и выше означенными институтами в разные исторические периоды в России складывались поразному.

В эпоху СССР в стране существовала устойчивая система государственных и профессиональных праздников, в то время как религиозные праздники на этапе борьбы государства с религией, т. е. в 20-е - начале 50-х годов прошлого века, в Советском Союзе отмечались населением тайком, а потом (в 60-е - 70-е годы, в хрущевскую оттепель» и брежневскую «эпоху застоя») - как бы «между прочим». Но с каждым новым поколением 
людей, так и не ставших, вопреки чаяниям советской власти, единой общностью - советским народом, массовый интерес к православным праздникам и обычаям как проявлению веры титульной нации, т. е. русских людей, неизменно падал. Традиция отмечания таких праздников мельчала, т.к. перестала быть всеобщей, а проявлялась как личное или семейное дело каждого желающего ее поддерживать [5].

Переход России в 90-е годы ХХ века в статус нового государства, резкие трансформации в политике, экономике, социальных отношениях и культуре не могли не повлиять на важные изменения современного праздничного календаря. Вопервых, с этого времени «все праздники за исключением, пожалуй, Нового года перестали быть всеобщими» [6, с. 98]. В наши дни таким всеобщим праздником становится День Победы. Вовторых, в праздничный календарь современных россиян вошли православные праздники, поскольку за последние десятилетия увеличилась значимость православной церкви. Заметим, что данный процесс коснулся в России и других конфессий и их праздников, но в данной статье они не рассматриваются. Нам важно отметить, что в наше время православные праздники, памятные православные даты и особые дни, связанные, например, с постами, есть в каждом месяце календарного года современного российского праздничного календаря. В-третьих, любой крупный праздник стал поводом для маркетинга, как и подобает обществу потребления [7], где любая акция по продаже «чего бы то ни было» рядится в одежды праздника, либо фестиваля, который тоже является праздничной формой [8]. Более того, поводом для современного праздника или фестиваля часто является не только историко-культурное или конфессиональное событие, либо местный артефакт, продукт, имеющий давнюю для этой территории традицию его обнаружения или производства. Часто таким поводом становится имиджевая торговая продукция в виде, скажем, сыра, мёда и т. д., которая, если еще не является брендом региона, о нем заявляющего, то, по крайней мере, стремится стать таким брендом. Так у современного праздника не просто возникает, а преобладает не совсем свойственная ему функция пользы, прагматики, поскольку история праздника указывает на него как на форму, прежде всего культуры духовной, выражающей душу, менталитет народа [2]. Безусловно, прагматика жизни присутствовала в традиционных народных праздниках, но она была «спрятана» за магическим «кружевом» ритуалов, обрядов, совершающихся в ходе праздничного действа для того, чтобы дети родились, чтобы был урожай, чтобы скот водился [9]. Но сакральное ядро традиционного праздника не позволяло модусу пользы выйти на первый план. С другой стороны, относясь скептически к крупной торговой акции, продвигаемой ее организаторами в формате праздника или фестиваля, следует помнить, что продвижение православных праздников в современную культурную жизнь особенно сельского населения вряд ли обойдется без технологий социального маркетинга. Задача данной статьи - показать, как это может произойти на практике.

Отметим, что, работая в таком сложном проблемном поле, касающемся проведения православных праздников в наши дни, организатору социально-культурной деятельности в сельских условиях для эффективности своей работы следует получить ответ на ряд вопросов. Во-первых, что такое православные праздники? Во-вторых, зачем их надо продвигать в социально-культурное пространство не только города, но и села? В-третьих, можно ли быть уверенным в том, что сельское население в силу своего культурного традиционализма более охотно, чем городское, воспринимает факт возвращения в свой праздничный календарь православных праздников; как на это откликаются учреждения культуры села? В-четвертых, как технологично обеспечить процесс этого продвижения в сельской местности с учетом скудости материально-технических, финансовых и кадровых ресурсов учреждений культуры, несмотря на объединение разных типов этих учреждений и создание сельских многофункциональных культурных центров?

Православные праздники - это «дни, посвященные церковному прославлению самых значительных с точки зрения православия религиозных событий или чествованию наиболее чтимых православием персон. Эти праздники по объекту прославления подразделяются на господни, богородичные и в честь святых, по торжественности - на великие, средние и малые» [10, с. 354-355]. Зачем нашим современникам нужно знать и помнить об этих религиозных событиях, святых и их деяниях? Видимо в этой информации содержится не просто норма человеческого поведения, но и нравственный идеал человека определенной веры, овеянный исторической традицией, конфессиональной легендой [11], а знание своих религиозных корней в наши дни многим людям по разным причинам необходимо. Отмечаются ли православные праздники и памятные даты в современной ситуации сельским населением, например, в Алтайском крае не только как домашняя традиция, а как организованные сельскими учреждениями культуры мероприятия? В этой связи интересны данные, собранные в монографическом исследовании 2016 г. [12]. Они позволяют отследить разнообразные формы 
Культура в евразийском пространстве: традищии и новащии. № 1 (4) 2020 2.

социально-культурных мероприятий, проектов, акций, совместно проведенных сельскими клубами, библиотеками, музеями в Алтайском крае в период с 2009 по 2015 гг. по различным направлениям воспитательной работы. Этот материал показывает, что из 96 форм мероприятий всего 5 было посвящено отмечанию следующих дат православного календаря: Крещение, День славянской письменности и культуры, 700-летие со дня рождения Преподобного Сергия Радонежского и два мероприятия, посвященные памяти святых Петра и Февронии Муромских как православного персонифицированного символа Дня любви, семьи и верности, отмечаемого 8 июля каждого года. Не случайно для светского Дня любви, семьи и верности как новой праздничной даты выбран день 8 июля, когда православные верующие отмечают день памяти этих святых, живших в Муроме в конце XII - начале XIII вв. Видимо, православная дата 8 июля содержит посыл к современным российским семьям и населению в целом, включающий информацию, о том, что в истории православия в России есть пример семейной пары святых людей с непростой жизненной историей любви и верности, творящей чудеса, который достоин изучения и прославления нашими современниками. Но в общем можно утверждать, что календарь организованных учреждениями культуры сибирского села православных праздников и памятных дат с точки зрения их количества оставляет желать лучшего.

Думается, что в этой связи важно не только количество организованных в условиях села православных праздников, но и главное - их качество, которое достигается квалифицированной технологией организации таких праздников на основе социального маркетинга, ориентированного не на прибыль, как в бизнесе, а на грамотный расчет ресурсной базы любого мероприятия [13; 14]. Проблема ресурсного обеспечения сельского праздничного мероприятия важна в двух аспектах: 1) насколько немногочисленный персонал объединенных учреждений культуры села владеет проектной технологией организации любых, в том числе - православных праздников; 2) каково материально-техническое и финансовое обеспечение этих мероприятий, или точнее - где взять средства для организации качественного праздничного мероприятия в селе?

Рассмотрим этот вопрос на примере анализа опыта проведения фестиваля и праздника, связанных с православной тематикой и организованных сельскими учреждениями культуры в двух разных районах Алтайского края. Обе ситуации явились поводом для выпускных квалификационных работ на бакалавриате и в магистратуре по направлению подготовки «социально-культурная деятельность». Это обстоятельство важно, поскольку в качестве организаторов мероприятий действовали не случайные, а специально подготовленные люди, работающие в штате своих учреждений культуры и одновременно являющиеся студентами выпускных курсов кафедры социально-культурной деятельности Алтайского государственного института культуры.

Создание проекта, либо программы организации праздничного события на основе социального маркетинга предполагает анализ социальнокультурной ситуации, в которой будет протекать организационный процесс. Это нужно для того, чтобы определить сильные и слабые его места (проблемы) и наметить ресурсы для устранения или минимизации слабых мест и оптимизации мест сильных.

В нашем случае, это событие - межрайонный сельский фестиваль художественного творчества, посвященный Дню любви, семьи и верности, как уже было упомянуто выше, он отмечается в России 8 июля, в день памяти святых Петра и Февронии (Ефросиньи). Другое событие - организация народного гуляния в честь празднования Петровок, Петрова Дня, точнее - Дня равноапостольных святых Петра и Павла. Он отмечается 12 июля по новому стилю, в этот день в светском праздничном календаре России отмечается также День рыбака. Заметим, что оба события происходят летом, что создает благоприятные условия для проведения фестиваля и праздника в естественной ситуации, «под открытым небом», т. е. с максимальным использованием такого ресурса, как сельский природно-ландшафтный комплекс. Исследователи проблемы возрождения традиционных самодеятельных форм культурнопросветительной работы еще в 80-е годы прошлого века недаром утверждали, что для возрождения культурно-исторических традиций как нельзя лучше подходит естественная среда их бытования, а не только и не столько сцена сельского клуба [15].

Разница исходных ситуаций состоит в том, что фестиваль имеет административную (оптимальную финансовую) поддержку местной муниципальной власти, выполняющей программу федеральных властей по поддержке российской семьи, проводится он не один год, расширил свои масштабы до рамок межрайонного сельского фестиваля. Народные гуляния в честь Петровок проектируются в другом сибирском селе впервые, с опорой на единственный ресурс - деятельность фольклорного коллектива, работающего много лет на базе местного клубного учреждения, сейчас преобразованного в многофункциональный 
культурный центр. Разница исходных ситуаций требует и разницы в технологии организации каждого из анализируемых событий с точки зрения маркетингового подхода, хорошо разработанного у А. П. Маркова [16].

Проблемной ситуацией для проведения фестиваля в честь Дня любви, семьи и верности явилась не только общероссийская проблема массового распада семей и необходимость укрепления российской семьи, но и местная проблема восполнения дефицита культурных событий в селе в летнее время. Она была важна для учреждения культуры конкретного райцентра Алтайского края, как инициатора фестиваля. Для местной власти, обеспечивающей административную поддержку организации фестиваля в роли его заказчика, важна была проблема продвижения своего имиджа в глазах односельчан и вышестоящих властных структур. Для населения как целевой аудитории проекта было интересным и на первых порах новым обстоятельством возможность посетить большое по масштабности культурное мероприятие. Отдельные сегменты этой аудитории (например, участники местной художественной самодеятельности) могли принять участие в подготовке концертной программы, другие - изготовить для разрешенной продажи определенную сувенирную продукцию, обеспечить за небольшую оплату размещение и питание приехавших на фестиваль его гостей зрителей из других сел этого района.

Форма фестиваля в виде именно художественно-творческого его вида (известно, что разновидностей фестивалей в наши дни существует множество) определила содержание этого празднества как показа достижений в области самодеятельного художественного творчества. Ведущей целевой установкой фестивального события стала установка идеологического и воспитательного характера: корректировка ценностных ориентаций сельского населения в сторону понимания государственной и личной важности крепкой семьи. Сценарный план этой социальной маркетинговой акции включал: 1) открытие и закрытие, обставленные как торжественные ритуалы для создания атмосферы важности события и значимости его гостей; 2) театрализованный концерт с квалифицированными ведущими, использованием технических аудиовизуальных средств и т. д.; 3 ) торговлю сувенирами и конкурсно-игровые эпизоды для зрителей с призами и бонусами за победу; 4) наличие основного события фестиваля в виде легенды о Петре и Февронии (легенду театрализовали); 5) разработка основного ритуала мероприятия - поздравление и символическое награждение местных семейных пар в различных номинациях (например, многодетных) и детей войны.
Безусловно, важна и требует ресурсного обеспечения изобразительная (цветок ромашки) и звуковая атрибутика акции. Кроме того, умельцы могут придумать и создать местный сувенирный символ фестиваля для продажи на память о событии.

Отдельно продумывается и ресурсно обеспечивается такая часть социальной маркетинговой акции, как ее реклама (бесплатное оповещение в местной районной газете о дате и месте проведения акции; пригласительный билет наиболее именитым гостям с логотипом мероприятия; программа фестиваля, отпечатанная на цветном принтере, которая тоже может выполнить функцию «сувенира на память» и т. д.).

Результатом маркетинговой акции является подсчет выгоды, которую получил каждый сегмент аудитории события, а также его инициатор и заказчик. Далее эти выгоды сравниваются с затраченными ресурсами и определяется маркетинговый результат акции в целом. Жители райцентра, например, получили выгоду как зрители бесплатного концерта, которые к тому же получили бонус - бесплатное угощение (сладкий стол) от спонсоров - местных предпринимателей. Другая часть жителей продала сувениры своего изготовления, обеспечила оплаченной едой и таким же ночлегом гостей фестиваля. Местные средства массовой информации и школа реализовали партнерскую поддержку акции в виде бесплатного размещения рекламы о ней в местной газете, подготовки конкурса рисунков школьников на тему крепкой семьи. Местная власть повысила свой рейтинг, вручив небольшие подарки чествуемым семьям (за счет средств районного бюджета по статье «Общерайонные мероприятия»). Многофункциональный центр культуры, являющийся инициатором акции, получил выгоду в виде выполненного пункта плана по подготовке и проведению пятого межрайонного сельского фестиваля. Кроме того, Центр решил задачу пополнения своих художественнотворческих коллективов новыми участниками, обеспечил привлечение сельских зрителей на их концерты на ближайшее будущее.

Следует отметить, что ресурсный вклад инициатора акции был наибольшим по сравнению с другими сегментами участников фестиваля. Работники этого учреждения культуры ресурсно обеспечивали: 1) оборудование и оформление концертной площадки; 2) подготовку технической аппаратуры и инструментов; 3) разработку программы театрализованного концерта; 4) репетиции и обеспечение сценическими костюмами выступающих; 5) приобретение призов и сувениров для зрителей как участников игровых конкурсов. С учетом, что каждый год все эти ресурсы надо обновлять, иначе интерес к акции погаснет, а на 
Культура в евразийском пространстве: традиции и новащчии. № 1 (4) 2020 2.

постоянную спонсорскую поддержку рассчитывать не приходится в силу небольших финансовых возможностей малого сельского бизнеса, инициатору акции следует обдумать возможность выдвижения данного фестиваля на грантовый конкурс.

Видимо, такое же решение об участии в грантовом конкурсе следует принять инициатору другой сельской маркетинговой программы, цель которой - организовать не просто концерт местного фольклорного коллектива, но попытаться возродить в конкретном сибирском селе православную традицию народного гуляния в честь Петровок [9, с. 616], о чем мы упоминали выше. Такое затратное по ресурсам мероприятие вряд ли будет реализовано в сельских условиях, если его организаторами не будет найден важный повод для того, чтобы оно состоялось. Например, следует попытаться интегрировать это событие в сферу туризма (такой опыт на Алтае есть [17]), т. е. сделать это событие культурно-исторической программой для продажи ее туристам как часть пакета туристических услуг. Далее следует обдумать форму реализации программы: 1) можно сделать ее как культурно-историческую реконструкцию крестьянского праздника в Сибири - народных гуляний; 2) или как театрализованную фольклорную программу на эту же тему, но уже без более глубокого погружения в изучение и максимально точное восстановление события, существовавшего в культуре сибирской деревни. В любом случае любой формат разработки темы может стать поводом для написания грантовой заявки.

В отличие от ситуации, касающейся организации сельского фестиваля, где православная информация о Петре и Февронии - это только небольшой элемент, на котором строится фрагмент (пролог) театрализованного концерта, в маркетинговом проекте празднования Петровок значительную часть должен занимать подготовительный период. Он касается сбора и изучения специальной информации о православных праздниках летнего цикла, об особенностях их бытования в Сибири [18]. Важен также и следующий этап подготовка фольклорной программы художественно-творческим коллективом учреждения культуры. Она включает песенно-хороводную и игровую части, а также обрядовую часть, связанную, например, с обрядом похорон Костромы (чучела из соломы и рогож) [19], обходов дворов для того, чтобы славить хозяев, исполняя специальную обрядовую песню «Виноградье красное», где слово «виноградье» означало - сады. На этих этапах понадобятся значительные ресурсы: оплата работы специалистов по сибирскому фольклору, изготовление атрибутики и костюмов для фольклорного коллектива и т. д.
Как и в предыдущем проекте, в ситуации, связанной с программой празднования Петровок, просчитывая выгоды, следует помнить, что они могут значительно увеличиваться и даже принести прибыль (а это будет уже не социальный, а просто маркетинг), если отснять хорошо подготовленную программу и выставить по подписке в Интернете. В этом случае работникам учреждения культуры скорее придет на помощь местная сельская молодежь, интересующаяся и хорошо владеющая современными электронными коммуникациями.

Одним словом, маркетинговый подход позволяет инициаторам проектов и программ, продвигающим православную праздничную тематику в социально-культурное пространство современного сибирского села, определиться насколько это по силам учреждениям культуры, чтобы попытаться найти выход из трудных ситуаций и тем самым выполнить свою миссию.

\section{Список литературы}

1. Добринская Е. И., Соколов Э. В. Свободное время и культура личности. Ленинград, 1983. $32 \mathrm{c}$.

2. Хренов Н. А. Культура в эпоху социального хаоса. Москва, 2002. 448 с.

3. Бахтин М. М. Творчество Франсуа Рабле и народная культура Средневековья и Ренессанса. Москва, 1965. $527 \mathrm{c}$.

4. Фурсова Е. Ф. Традиции поведения сельских престольных праздников в Приобье (конец XIX - начало XX вв.) // Вопросы краеведения Новосибирска и Новосибирской области. Новосибирск, 1997. С. 175-181.

5. Воловик А. Ф., Воловик В. А. Педагогика досуга. Москва, 1998. 240 с.

6. Яковенко И. Г. Город в пространстве диалога культур и диалог города // Социокультурное пространство диалога. Москва, 1999. С. 90-101.

7. Граф Джс., Ванн Д., Нейлор Т. Х. Потреблятство. Болезнь, угрожающая миру. Москва, 2003. $256 \mathrm{c}$.

8. Белинская О. Н., Оленина Г. В. Фестивали народного художественного творчества в контексте сохранения и трансляции этнокультурного наследия // Мир науки, культуры, образования. 2016. № 5. С. 179-181.

9. Поэзия крестьянских праздников // Библиотека поэта. 2-е изд. Ленинград, 1970. 640 с.

10. Атеистический словарь. 2-е изд. Москва, 1985. 512 с. Из содерж.: Православные праздники. С. 354-355.

11. Кураев A. Человек перед иконой // Квинтэссенция. Москва. 1992. С. 245-263.

12. Оленина Г. В. Фролова А. С. Интеграция деятельности учреждений культуры села как 
фактор оптимизации досуга населения: история, теория, практика. Барнаул, 2016. 199 с.

13. Сочиальный маркетинг // Тульчинский Г. Л. Менеджмент в сфере культуры. СанктПетербург, 2001. С. 141-158.

14. Годин А. М., Максимова Н. С., Подпорина И. В. Маркетинг. Москва, 2004. 728 с.

15. Смирнова Е. И. Теория и методика организации самодеятельного творчества трудящихся в культурно-просветительных учреждениях. Москва, 1983. 192 с.

16. Марков А. П. Проектирование маркетинговых технологий. Рекламные технологии. Связи с общественностью. Спонсорская деятельность. Ростов-на-Дону, 2006. 543 с.

17. Олейник Я. А. История Всероссийского фестиваля «Шукшинские дни на Алтае» в аспекте интеграции культурно-исторического наследия в сферу туризма // Мир науки, культуры, образования. 2014. № 6. С. 488-491.

18. Хороводные и игровые песни Сибири. Новосибирск, 1985. 246 с.

19. Даль В. И. Толковый словарь живого великорусского языка : [в 4 т.]. Москва. Т. 2. 1979.780 с. Из содерж.: Кострома С. 176.

УДК 001.895:[793.3:378.1](571.1)

DOI: $10.32340 / 2514-772 X-2020-1-69-72$

Г. В. Бурцева, кандидат педагогических наук, доцент Алтайский государственный институт культуры (Барнаул, Россия) burtseva-1957@mail.ru

\section{К ИССЛЕДОВАНИЮ ХОРЕОГРАФИЧЕСКИХ НОВАЦИЙ В ОБРАЗОВАТЕЛЬНОМ ПРОСТРАНСТВЕ АЛТАЙСКОГО РЕГИОНА}

Аннотация. Изложены предварительные результаты изучения эффективности внедрения экспериментальных хореографических новаций в образовательный процесс, организованный на хореографическом факультете Алтайского государственного института культуры (г. Барнаул Алтайского края, Россия) в рамках реализации многолетней научно-исследовательской и культурно-просветительной программы лаборатории «Мастерство хореографа», действующей на факультете. Освещены основные результаты работы регионального «круглого стола» по теме «Современный танец на Алтае: история, проблемы и перспективы развития» (Барнаул, 2019 г.), активными участниками которого стали ведущие преподаватели института в области современной хореографии, а также руководители современных профессиональных и любительских хореографических коллективов Алтайского края. В научный оборот впервые вводятся малоизвестные данные из истории становления и развития современного танца в регионе. Представлен авторский взгляд на основные направления дальнейшего научно-практического осмысления достижений современного танцевального искусства в регионе как вида хореографической новации в учебно-воспитательном процессе современной образовательной организации высшего образования.

Ключевые слова: новации в хореографии, хореографическое образование, современный танец, современное любительское хореографическое творчество, любительские хореографические коллективы, личные документные архивы.

На современном этапе в системе хореографического образования можно обнаружить две стратегии обучения: традиционную и инновационную (альтернативную). Бесспорным является тезис о том, что инновационный тип обучения и инновационная среда благоприятно влияют на проявление креативных свойств личности обучающегося, развитие разнообразных форм мышления (аналитического, проектного, концептуального и др.). Готовность к творческому сотрудничеству в новых ситуациях является важным профессиональным качеством выпускника-хореографа. Именно инно- вационная модель обучения стимулирует активный отклик на совместную проектную деятельность преподавателя и студента.

Опираясь на современную педагогическую парадигму и значимые для нас исследования в области теории и практике инноваций в плане управления и проектирования инновационных моделей профессионального обучения $[1,2]$. Опираясь на данные науки, авторский опыт развивает модель обучения бакалавров-хореографов в контексте инновационной методики преподавания хореографических дисциплин. Разработка и реали- 